\title{
Laser Propagation in Saltwater Ice
}

Jacob R. Longacre and Mark A. Landry

Submarine Electromagnetic Systems Department, Code 3422

Naval Undersea Warfare Center, Detachment New London

39 Smith Street, New London, CT 06320

T: 203.440.5105 Fax: 203.440.6725

\section{ABSTRACT}

Knowledge of the optical properties of sea ice is critical for optical remote sensing analysis, under-ice bio-optical variability measurements, and climatological polar energy balance research However, optical propagation in sea ice is not well characterized. The optical properties of sea ice are affected by many variables including ice thickness and morphology, dissolved and particulate components, and growth conditions. Inherent optical properties of ice are difficult to measure in situ, but these properties change when the ice is removed from its environment.

The objective of this research was to measure the optical characteristics of saltwater ice as a function of its morphological and physical properties. In order to conduct these measurements, an optical apparatus was constructed to direct a pulsed, frequency doubled Nd:YAG laser beam (emitting at $532 \mathrm{~nm}$ ) downward onto a selected spot on the air-ice interface. Avalanche photodiodes were used to map spatial profiles of the laser light transmitted through and backscattered from the ice. From January through March of 1993, we conducted in situ laser propagation studies on saline ice grown in an outhoor pool. Backscatter and transmission profiles were measured as a function of the ice properties.

\section{INTRODUCTION}

The goal of this research is to analyze the mechanisms and processes that link the morphological/physical and the electromagnetic properties of sea ice. The results can be used to advance the accuracy of predictive models for light penetration through ice, determine the feasibility of remote measurement of sea ice physical properties from airborne or spaceborne platforms, and interpret biological effects of ice and snow cover. However, the optical structure of sea ice is complex and influenced by a number of environmental factors. In order to determine specific causal relationships, we need to study ice grown under controlled, well documented conditions. Therefore, we conducted investigations of saline ice grown in an outdoor ice pool.

\section{TECHNICAL APPROACH}

From January through March of 1993, NUWC Code 3422 conducted in situ optical propagation studies with downwelling laser radiation to determine the optical properties of young saline ice for the duration of its growth cycle. These measurements were made on saline ice grown in an outdoor pool at the Cold Regions Research and Engineering Laboratory (CRREL). To avoid changes that occur in optical characteristics of inhomogeneous saline ice when removed from its environment, we conducted these downwelling laser propagation experiments in situ. Most of our testing was conducted after dark in order to minimize ambient light noise.

We constructed an optical apparatus that directed a frequency doubled, pulsed, diode-pumped Neodymium:YAG laser beam (10 $\mu \mathrm{J} /$ pulse, $1 \mathrm{~kW}$ peak power, $10 \mathrm{~mW}$ average power @532 nm) downward onto the air-ice interface. This apparatus is illustrated in figures 1 and 2 . The apparatus contained detector mounts that could be positioned horizontally at known locations above or below the ice cover. The detector mounts were adjustable so that spatial profiles of the reflected laser light could be measured as a function of detector look angle. Avalanche photodiodes (APDs) on these detector mounts were used to map spatial profiles of the light transmitted and backscattered from the laser beam. These detectors had fields of view of approximately $2^{\circ}$. Interference filters were fitted io the APD detectors to minimize ambient light noise. Backscatter profiles were measured both as a function of time (ice thickness) and detector look angle. Transmission profiles were measured as a function of time. At the conclusion of the mapping experiments, blocks of ice near the test region were removed and studied to identify the structural features of the ice.

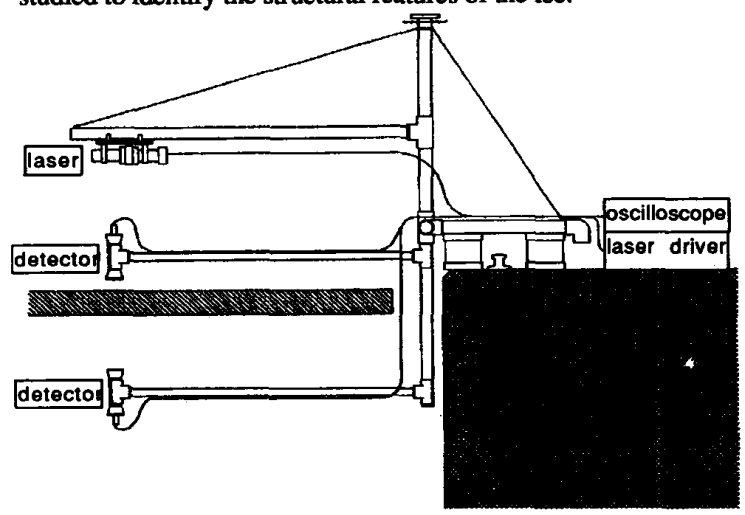

Figure 1

Optical apparatus diagram.

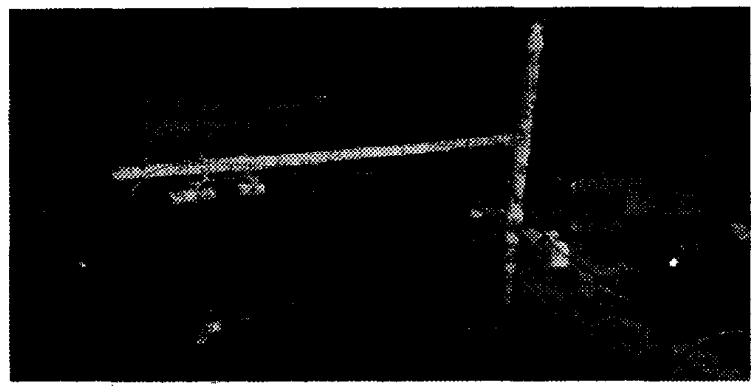

Figure 2.

Optical apparatus photograph.

\section{EXPERIMENTAL PROCEDURE}

The saline ice for this experiment was grown in a pool from water with a bulk salinity of approximately $30 \%$. Ice growth began on the evening of January 18, 1993. Our first transmission and backscatter measurements were taken on the evening of January 19 , when the ice thickness was approximately $3 \mathrm{~cm}$. However, failure of an optical fiber decreased signal strength for the transmission measurements and limited testing time. Testing was resumed early on the morning of January 20 with a new fiber optic cable. At this point the ice was approximately $5.6 \mathrm{~cm}$ thick. The transmission profile of a downwelling laser beam normally incident on the ice was measured with a detector suspended under the ice looking directly upward. Backscatter profiles were taken for detector look angles of $-8.8^{\circ}, 0^{\circ}, 8.8^{\circ}, 18^{\circ}, 27^{\circ}, 36^{\circ}$, and $45^{\circ}$, where $0^{\circ}$ represents the detector positioned vertically looking directly down at the ice. All subsequent series' of measurements included this set of profiles. 
The next series of measurements was taken on the night of January 26,1993 , when the ice was approximately $6.7 \mathrm{~cm}$ thick. A set of transmission and backscatter profiles was taken. A sample of ice was then removed for study. A dense layer of $1 \mathrm{~mm}$ diameter bubbles was visible just below the surface of the ice.

The third series of transmission and backscatter profile measurements was taken on the night of February 4, 1993, when the ice was approximately $10.5 \mathrm{~cm}$ thick. Between January 26 and February 4, snow had fallen on the ice. The snow was removed from the ice, but brine wicking into the snow, and melting and refreezing of some of the snow may have occurred. When a block of ice was removed at the end of testing, bubbles were visible throughout the top $2 \mathrm{~cm}$ of the ice.

The fourth series of transmission and backscatter profile measurements was taken on the night of February 18, 1993, when the ice was approximately $19 \mathrm{~cm}$ thick. A mixture of snow and slush was on top of the ice. A transmission profile was taken through the ice, snow, and slush. Then the snow and slush were removed from the ice in the test area, and a set of transmission and backscatter profiles was taken. Then a block of ice was removed for study. The ice was not as rigid as it had been two weeks before. It was softer and much more porous. Brine trickled out of the ice block when it was removed from the water. The bottom of the ice block had a coarse dendritic crystal layer.

The fifth series of transmission and backscatter profile measurements was taken on the night of March 11, 1993. The ice had melted somewhat, decreasing thickness to approximately 17.5 $\mathrm{cm}$. A fter transmission and backscatter profiles were taken, a block was cut from the ice. Brine drained out of the ice block when it was removed from the water. The bottom layer of the ice block contained a coarse series of gaps and cracks. After the block was removed, a transmission profile was taken for open water.

\section{RESULTS}

Transmission Profiles

Transmission profiles are shown with actual signal levels in figure 3 and normalized signal levels in figure 4 . The optical signal was low on January 19 due to a faulty optical fiber. However, comparison of the normalized transmission profiles shows that the January 19 transmission profile falls between that of open water and the profile taken on January 20 . The similarity of the normalized profiles for January 19 and for open water suggest that very little volume scattering was occurring in the ice at that time. This agrees with physical observations. On January 19, the ice was

transiuscent, and the laser beam could be seen propagating through it. Very little spreading was visible.

Beamwidth (measured at FWHM) was greatest on January 26 and February 18. The beamwidth on February 18 can be largely attributed to ice thickness. However, on January 26 , the ice was less than $7 \mathrm{~cm}$ thick. Also, the shape of the transmission profile measured on January 26 does not follow the shape common to previous transmission profiles of saline ice (Gilbert and Schoonmaker, 1990). The large beamwidth and atypical shape may have been caused by the dense bubble layer observed at the surface of the ice on January 26. Ambient temperatures were high from January 21 through 25 (figure 5). Melting and refreezing of the surface layer of the ice can produce a bubbly layer of low salinity ice. It is evident from figure 6 and the CRREL ice salinity measurements (Gow and Perovich, 1993) that by January 26 the salinity of the top few millimeters of ice dropped to less than half of its value on January 20 . Because the bubble layer was right at the surface of the ice, and the bubble size was comparable to that of the laser spot on the ice ( $1 \mathrm{~mm}$ bubbles and a $3 \mathrm{~mm}$ laser spot size), the bubbie layer could cause sufficient scattering to produce the large beamwidth and atypical profile shape observed.

Excluding the transmission profile for January 26, beamwidth increased with time and ice thickness through February 18. However, the transmitted beamwidth measured on March 11 was less than that measured on February 4 and 18. This is due to the fact that the ice had begun to melt and refreeze by March 11 . Average temperatures from March 1 to 11 were high (figure 5). The thickness of the ice decreased since February 18. Also, the brine channels that were already forming by February 18 were much more extensive by March 11, as indicated by the rapid rate at which the brine drained from the ice block on March 11. As shown in figure 6 , the salinity of the ice decreased significantly since February 18. At this point, the ice characteristics were between those of new and multiyear ice, with significant decreases in volume scattering and transmission loss.

signal (mV)

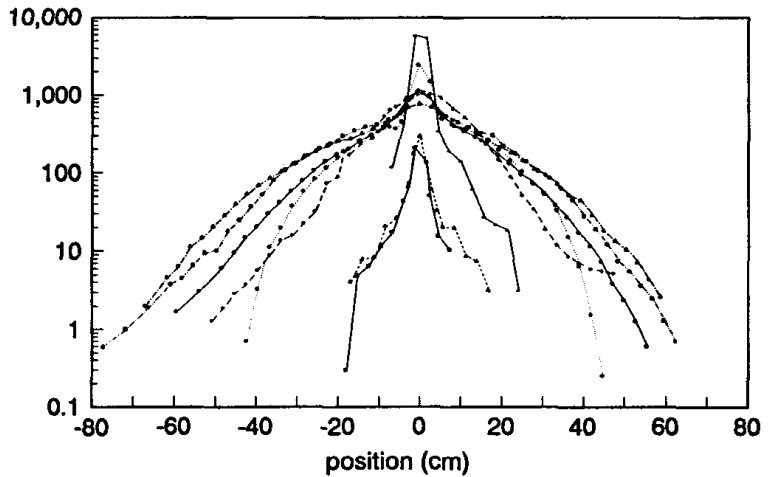

$3.0 \mathrm{~cm} 3.0 \mathrm{~cm} 5.6 \mathrm{~cm} 6.7 \mathrm{~cm} 10.5 \mathrm{~cm} 19.0 \mathrm{~cm} 17.5 \mathrm{~cm}$ open water 19JAN 19JAN 2OJAN 26JAN 4FEB 18FEB 11MAR IIMAR

Figure 3.

Saline ice transmissiun profiles

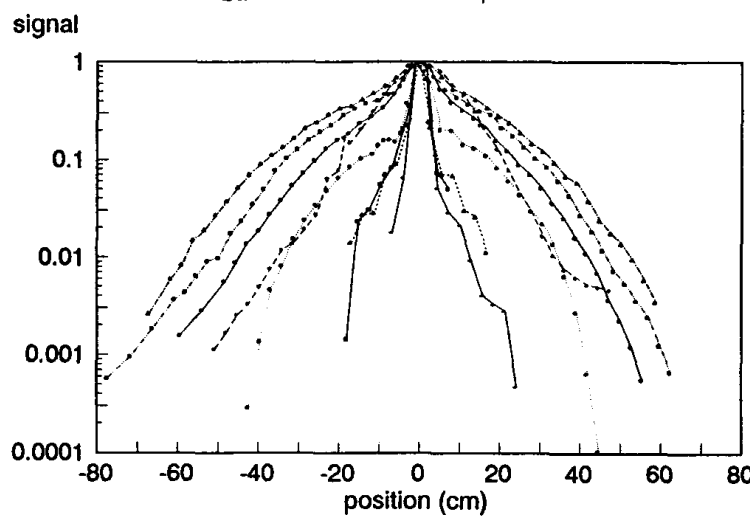

$3.0 \mathrm{~cm} 3.0 \mathrm{~cm} 5.6 \mathrm{~cm} 6.7 \mathrm{~cm} 10.5 \mathrm{~cm} 19.0 \mathrm{~cm} 17.5 \mathrm{~cm}$ open water 19JAN 19JAN 2OJAN 26JAN 4FEB 18FEB 11MAR 11MAR

Figure 4.

Normalized saline ice transmission profiles.

Temperature (C)

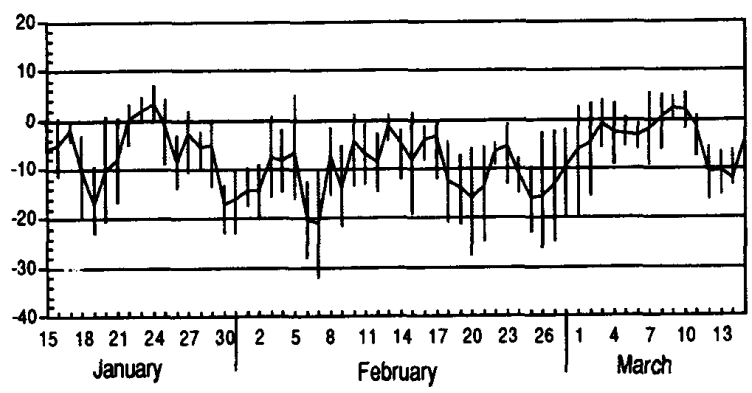

Figure 5

Ambient air temperature at CRREL facility for winter, 1993. 
Depth(cm)

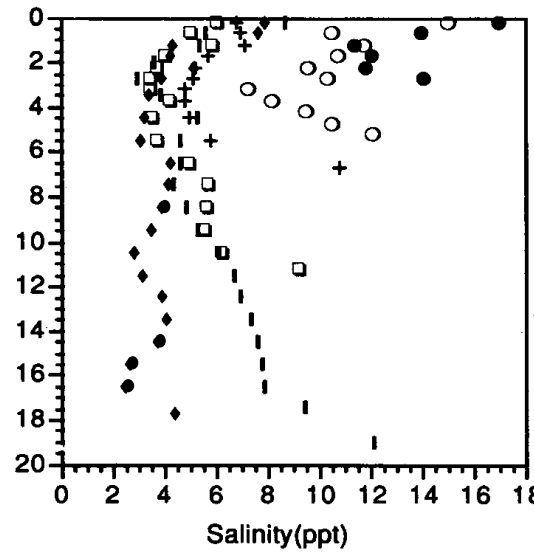

Figure 6.

CRREL Ice salinity as a function of depth.

\section{Backscatter Profiles}

For each series of measurements, backscatter profiles were taken for detector look angles of $-8.8^{\circ}, 0^{\circ}, 8.8^{\circ}, 18^{\circ}, 27^{\circ}, 36^{\circ}$, and $45^{\circ}$, where $0^{\circ}$ represents the detector positioned vertically looking directly down at the ice. The backscatter profiles for a detector look angle of $0^{\circ}$ are shown in figure 7. Gaps in the centers of the backscatter profiles are due to the detector blocking the laser beam. The backscatter profiles for January 19 and 20 are very narrow due to the smooth ice surface and limited volume scatter. The backscatter profile for January 20 is narrower than that of January 19 because high ambient temperatures (figure 5 ) and clear conditions on Jainuary 20 caused melting of the very top layer of the ice. The water on top of the ice formed a very smooth surface, thus increasing spectral scattering and decreasing diffuse scattering. From January 26 to February 18, the width the backscatter profiles increased slightly, then the width of the March 11 profile decreased slightly. However, once the bubble layer observed on January 26 developed, thus producing significant volume scattering, the $0^{\circ}$ backscatter profiles did not change significantly.

signal $(\mathrm{mV})$

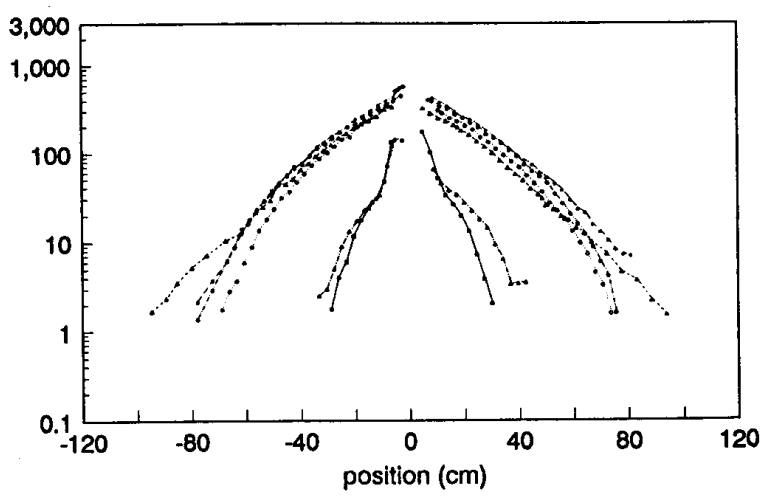

$3.0 \mathrm{~cm} 5.6 \mathrm{~cm} \quad 6.7 \mathrm{~cm} \quad 10.5 \mathrm{~cm} 19.0 \mathrm{~cm} 17.5 \mathrm{~cm}$ 19JAN 2OJAN 2GAN 4FEB 18FEB 11MAR

Figure 7.

Backscatter profiles for a detector look angle of $0^{\circ}$.

The backscatter profiles were utilized to generate phase functions for points on the ice surface at different distances from the laser spot. These phase functions are shown in figure $\mathbf{8}$ for each set

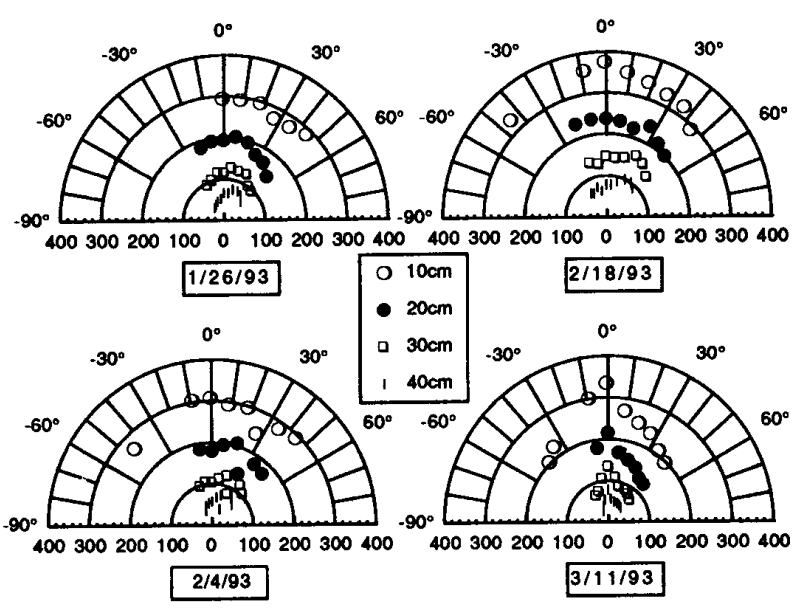

Figure 8.

Backscatter phase functions.

of measurements except those on January 19 and 20 . The backscatter profiles taken on January 19 and 20 were very narrow and had insufficient signal at the chosen points. The phase functions for January 26 show approximately isotropic scatter near the laser spot. The scattering becomes more anisotropic and the maximum intensity occurs at greater angles from the vertical as the distance from the laser spot increases. The phase functions for February 4 are similar except for a significant decrease in intensity at $27^{\circ}$. The phase functions for February 18 show anisotropic scatter with the maximum intensity at $0^{\circ}$ near the laser spot. At a point further from the laser spot, two maxima appear, one at $0^{\circ}$ and one that occurs at greater angles from the vertical as the distance from the laser spot increases. The phase functions on March 11 are all anisotropic with their maximum at $0^{\circ}$. This process may be caused by the columnar structure of the ice (Schwarz and Weeks, 1982). The light scattered from the columnar zone of the ice is preferentially scattered vertically. However, this effect would only be apparent when the columnar zone and the layers above it had too few scatterers to disrupt the preferential angular distribution of the light.

\section{CONCLUSION}

These investigations have shown that optical characteristics of young saltwater ice are affected by the growth history of the ice and are strongly influenced by ambient temperature. One possible source of error in this investigation is particulate matter. Particulates on the surface of the ice and embedded in the ice can significantly influence volume scattering (Fritsen and Iturriaga, 1992).

Particuiates of metal and chips of paint were visible in several of the ice blocks removed for study.

\section{REFERENCES}

Fritsen, C. H., Iturriaga, R.H., "Influence of particulate matter on spectral irradiance fields and energy transfer in the Eastern Arctic Ocean.", SPIE Vol.1750, Ocean Optics XI, 1992, pp. 527-541.

Gilbert, G.D., Schoonmaker, J., "Measurements of Beam Spread in New Sea Ice." SPIE Vol.1302 Ocean Optics X, 1990, pp.545-555.

Gow, A.J., Perovich, D.K., "Laboratory Investigations into the Structural and Physical Characteristics of Saline Ice Sheets and their Electromagnetic Properties." Cold Regions Report, 1993.

Schwarz, J., Weeks,W.F., "Engineering Properties of Sea Ice", Journal of Glaciology, 1981, pp. 499-531. 